\title{
Detection and Quantification of Protein Post-Translational Modifications Using Novel Microchannel Plate Autoradiographic Imagers
}

\section{Wayne Grant Carter*}

School of Graduate Entry Medicine \& Health, University of Nottingham Medical School, Royal Derby Hospital Centre, Derby DE22 3DT, UK

\begin{abstract}
It is likely that all proteins are modified post-translationally, either enzymatically or non-enzymatically. Scientists have continued to develop suitable methodologies in order to study the ever burgeoning list of protein post-translational modifications (PTMs). For the study of PTMs, one must consider suitable assays by which the target protein can be detected, the site(s) of PTM determined, the stoichiometry and stability of the PTM evaluated, and the biological outcome of the modification assessed. Historically, one of the methods of choice for identifying which protein is modified, and the site and stoichiometry of modification, has been the utilisation of commercial radiochemicals. Of these, tritium $\left({ }^{3} \mathrm{H}\right)$ has excellent potential to facilitate analyses of biochemical reactions, but has the weakest signal strength of the commonly employed biological $\beta$-emitters. Hence development of imaging devices that are superior to conventional film autoradiography will enable a better exploitation of the universal application of ${ }^{3} \mathrm{H}$ for measuring PTMs. Herein, we discuss the current application of film autoradiography and the advantages of using microchannel plate (MCP) autoradiographic imagers.
\end{abstract}

Keywords: $\beta$-emitter; Microchannel plate; Post-translational modifications

\section{Introduction}

The most commonly employed laboratory radiochemicals for studying biological systems are $\beta$-emitters; including tritium $\left({ }^{3} \mathrm{H}\right),{ }^{14} \mathrm{C}$, ${ }^{35} \mathrm{~S}$, ${ }^{33} \mathrm{P}$, and ${ }^{32} \mathrm{P}$. These $\beta$-emitters differ in their energetic strength, with ${ }^{3} \mathrm{H}$ being the weakest $\beta$-emitter, rising to ${ }^{32} \mathrm{P}$, the strongest (Table 1 ). By using a $\beta$-emitter of relatively high strength there will likely be a corresponding reduction in autoradiographic exposure time. However, the relatively stronger (more penetrative) $\beta$-emission from ${ }^{32} \mathrm{P}$ is potentially hazardous to the experimenter, and therefore laboratory work is confined to behind $1 \mathrm{~cm}$ of perspex shielding. Radioactivity safety practices are still required for ${ }^{3} \mathrm{H}$ use, but user-shielding is not required. For laboratory studies, one will also need to consider the timeframe of experimentation: ${ }^{32} \mathrm{P}$ has a half-life of 14.3 days, so optimal radiolabel usage is restricted. By comparison ${ }^{3} \mathrm{H}$ has a half-life of 12.4 years, so although both of these radiochemicals may be susceptible to hydrolysis and decomposition, there is much less restriction on laboratory shelf-life with ${ }^{3} \mathrm{H}$. Additionally, although ${ }^{32} \mathrm{P}$ has proved an invaluable asset for the study of phosphate transfer in the dynamic activity of kinases and phosphatases, it has less universal application to the study of other biomolecules. By contrast, organic molecules that contain a hydrogen atom may in theory be labeled to form a tritiated derivative. Thus ${ }^{3} \mathrm{H}$ can be more extensively utilized in biomolecular studies than ${ }^{32} \mathrm{P}$

\section{Methodology}

One major drawback of ${ }^{3} \mathrm{H}$ use is that its weak signal strength may require signal amplification for detection. The weak $\beta$-emitter energy of ${ }^{3} \mathrm{H}$ can be harnessed as photons in liquid scintillation counting (LSC), or fluorometric autoradiography. To determine which protein is modified within a protein mixture, protein resolution by SDS-PAGE is commonly employed, but direct ${ }^{3} \mathrm{H}$ escape for autoradiography is limited. Several steps can be undertaken to improve the weak emission of ${ }^{3} \mathrm{H} \beta$-emitters to provide suitable autoradiography. After ${ }^{3} \mathrm{H}$-radiolabelled protein resolution by SDS-PAGE, the gel can be impregnated with a fluorophore, such as sodium salicylate and then the gel dryed. To improve linearity and sensitivity of a film signal, the film may also be preflashed and then autoradiography performed at a low temperature, typically $-80^{\circ} \mathrm{C}$. However, even with these additional measures to facilitate ${ }^{3} \mathrm{H}$ signal acquisition, exposure times of days to weeks may still be required to provide sufficient cumulative auto radiographic signal [1].

Contrary to these additional manipulations, the relatively strong $\beta$-emitter ${ }^{32} \mathrm{P}$ may only require short-term and direct auto radiographic exposure. Direct autoradiography of ${ }^{32} \mathrm{P}$ will afford sensitivity and resolution, but signal capture may also be enhanced using intensifying screens, although this will reduce signal resolution. By either direct autoradiography or from the use of intensifying screens, the superior signal strength of ${ }^{32} \mathrm{P}$ facilitates typical film autoradiography exposures of only hours to days, and as with ${ }^{3} \mathrm{H}$, this is usually accomplished from autoradiography at low temperatures $\left(-80^{\circ} \mathrm{C}\right)$. These major differences in the properties of ${ }^{3} \mathrm{H}$ and ${ }^{32} \mathrm{P}$ are summarized in table 2 . Hence, ultimately an improvement in the sensitivity of ${ }^{3} \mathrm{H}$ autoradiography will facilitate the broader exploitation of ${ }^{3} \mathrm{H}$ as a radiolabel used for the study of biological systems [1].

The current commercial market availability of instruments for sensitive ${ }^{3} \mathrm{H}$ imaging is not extensive. Commercial phosphor-imagers with plates suitable for ${ }^{3} \mathrm{H}$ are available, and alternatively, microchannel

\begin{tabular}{|l|l|l|}
\hline $\boldsymbol{\beta}$-emitter & Signal strength & Maximal energy $(\mathbf{M e V})$ \\
\hline${ }^{3} \mathrm{H}$ & Weak & 0.019 \\
\hline${ }^{14} \mathrm{C}$ & Weak & 0.156 \\
\hline${ }^{35} \mathrm{~S}$ & Weak & 0.167 \\
\hline${ }^{33} \mathrm{P}$ & Medium & 0.249 \\
\hline${ }^{32} \mathrm{P}$ & Strong & 1.709 \\
\hline
\end{tabular}

Table 1: Commonly employed laboratory $\beta$-emitters.

*Corresponding author: Wayne Grant Carter, School of Graduate Entry Medicine \& Health, University of Nottingham Medical School, Royal Derby Hospital Centre, Derby DE22 3DT, UK, Tel: +44 (0)1332 724738; Fax: +44 (0)1332 724626; E-mail: Wayne.Carter@nottingham.ac.uk

Received November 17, 2012; Accepted November 23, 2012; Published November 26, 2012

Citation: Carter WG (2012) Detection and Quantification of Protein PostTranslational Modifications Using Novel Microchannel Plate Autoradiographic Imagers. Med chem S11:001. doi:10.4172/2161-0444.S11-001

Copyright: (c) 2012 Carter WG. This is an open-access article distributed under the terms of the Creative Commons Attribution License, which permits unrestricted use, distribution, and reproduction in any medium, provided the original author and source are credited. 
Citation: Carter WG (2012) Detection and Quantification of Protein Post-Translational Modifications Using Novel Microchannel Plate Autoradiographic Imagers. Med chem S11:001. doi:10.4172/2161-0444.S11-001

Page 2 of 2

\begin{tabular}{|l|l|l|l|l|l|l|}
\hline B-emitter & $\begin{array}{l}\text { Relative Signal } \\
\text { strength }\end{array}$ & Half-life & Signal Containment & Biological analyses & $\begin{array}{l}\text { Signal } \\
\text { amplification }\end{array}$ & Film autoradiography \\
\hline${ }^{3} \mathrm{H}$ & 1 & 12.4 years & Bench work \& monitoring & $\begin{array}{l}\text { Organic molecules. PTMs e.g. } \\
\text { alkylation, methylation }\end{array}$ & Fluorometry \\
\hline${ }^{32} \mathrm{P}$ & 90 & 14.3 days & $\begin{array}{l}\text { User shielding behind } 1 \mathrm{~cm} \text { of } \\
\text { perspex }\end{array}$ & $\begin{array}{l}\text { Phosphate transfer. PTM as } \\
\text { phosphorylation }\end{array}$ & Intensifying screens & Hours-days \\
\hline
\end{tabular}

Table 2: Comparison of the physical properties and biological application of ${ }^{3} \mathrm{H}$ and ${ }^{32} \mathrm{P}$.

plates can provide the proximity sensor for ${ }^{3} \mathrm{H} \beta$-particles. Microchannel plate (MCP) autoradiographic imaging was developed independently at a number of sites, including the University of Leicester Space Research Centre [2-4]. In contrast to film autoradiography, MCP imagers have a lower radiolabel signal threshold (higher sensitivity) of only $6 \mathrm{dpm} / \mathrm{mm}^{2}$, and are able to detect radiolabel signal linearly over six orders of signal magnitude. Additionally, MCP radiolabel signal detection is in real-time, with an on-screen display, and this is operational at room temperature. Other useful properties of $\mathrm{MCP}$ imagers include low intrinsic background noise of $5 \times 10^{-6}$ counts/sec per pixel measurement, a spatial resolution of $\sim 70 \mu \mathrm{M}$, and an imaging window of $9.3 \mathrm{~cm}$ PROOF- $20359.3 \mathrm{~cm}$; suitable for 1D or 2D PAGE mini-gel visualisations, or the analysis of several standard microscopy slides in a single autoradiograph. Finally, the MCP imager has internal software which allows direct quantitation of pixel measurements without the need for further densitometric analysis.

\section{Results and Discussion}

The superior sensitivity and reduced exposure time of MCP imagers has enabled us to track protein post-translational modifications (PTMs) that would normally be difficult to detect, as they lie at or below the sensitivity threshold provided by conventional film autoradiography. For example, we have studied PTM (adduction) of proteins by commonly encountered commercial organophosphorus (OP) pesticides. Undesired exposure to environmental pesticides is a global health concern. The toxic effects of acute, substantive exposure may usually be attributed to frank cholinergic poisoning as a consequence of adduction to and inhibition of acetylcholinesterase (AChE) within nerve synapses. However, inadvertent protein adduction (covalent) or direct binding to other secondary proteins remains a health concern, and moreover, cumulative low-level exposure may result in ill-health without triggering detectable signs of cholinergic inhibition [1,5-7].

To track OP pesticide adduction of proteins in vitro, one would use individual radiolabelled pesticides, but they are not available commercially. A commercial OP, ${ }^{3} \mathrm{H}$-diisopropylfluorophosphonate $\left({ }^{3} \mathrm{H}\right.$-DFP) can be purchased, and we utilized this broad-binding OP to track pesticide adduction targets. Our strategy to detect pesticide PTM of proteins, under conditions of relatively low levels of AChE inhibition was to either dose animals with pesticide in vivo or preincubate animal tissue in vitro with pesticide, and then radiolabel any free OP adduction sites using ${ }^{3} \mathrm{H}$-DFP. Adduction of a protein target by a pesticide resulted in a reduction in subsequent ${ }^{3} \mathrm{H}-\mathrm{DFP}$ radiolabelling and this was quantified using MCP auto radiographic imaging. The imaging window of $9.3 \mathrm{~cm} \times 9.3 \mathrm{~cm}$ allowed us to autoradiograph ${ }^{3} \mathrm{H}$-DFP proteins that had been resolved by either $1 \mathrm{D}$ or $2 \mathrm{D}$ mini-gel PAGE.

The level of pesticide adduction (fall in ${ }^{3} \mathrm{H}-\mathrm{DFP}$ radiolabelling) was quantified in protein bands using the intrinsic MCP $\beta$-acquisition software. This software provides a direct quantitation of the pixel density (radiolabelling) across the length of a gel lane. Hence a direct comparison (and quantitation) of radiolabelling at each ${ }^{3} \mathrm{H}$-DFP protein band can be made between controls and test pesticide preincubations [1,5-7].
There is the potential to utilize this preincubation strategy to enable detection of other PTMs, but if radiolabels are available to monitor the PTMs directly this may not be required. As an example of this, we have followed PTM as carboxyl methylation, and after 2D-PAGE of radiolabelled methylation targets, we were able to identify novel targets of protein PTM [8]. If the targets of PTM lay below the threshold of protein visualization methods such as Coomassie or silver staining $(\sim 0.1 \mathrm{ng})$ then column chromatography may facilitate protein enrichment, with MCP autoradiography utilized to track the proteins of interest [1,5-7].

Finally, the imaging window is also of suitable size to enable simultaneous autoradiography of 3 glass microscopy slides. For a standard microscopy slide $(75 \mathrm{~mm} \times 25 \mathrm{~mm})$ we typically apply 3 tissue sections; hence 9 simultaneous images can be acquired in a single autoradiograph. We have utilized this rapid and sensitive imaging to examine brain microlocalisation of radiolabelled ligands in the mice brain [1]. From $\mathrm{H} \& \mathrm{E}$ staining of brain tissue sections visual landmarks provide an anatomical guide onto which the autoradiogram is superimposed to enable radiolabel localization.

In summary, ${ }^{3} \mathrm{H}$ has excellent potential for the study of PTMs of biological molecules, but there is a need for sufficiently sensitive equipment, such as MCP digital autoradiographic imagers to match and respond to the study of an ever expanding list of protein PTMs.

\section{Acknowledgements}

The author would like to thank the Medical Research Council and Syngenta for financial support for some of the research studies described in this manuscript.

\section{References}

1. Carter WG, Tarhoni M, Rathbone AJ, Ray DE (2007) Differential protein adduction by seven organophosphorus pesticides in both brain and thymus. Hum Exp Toxicol 26: 347-353.

2. Lees JE, Fraser GW, Carthew $P$ (1998) Microchannel plate detectors for $14 \mathrm{C}$ autoradiography. IEEE Trans Nucl Sci 45: 1288-1292.

3. Lees JE, Pearson JF (1997) A large area MCP detector for X-ray imaging. Nucl Instrum Methods Phys Res A 384: 410-424.

4. Lees JE, Fraser GW, Dinsdale D (1997) Direct beta autoradiography using microchannel plate (MCP) detectors. Nucl Instrum Methods Phys Res Sec A 392: 349-353.

5. Tarhoni MH, Lister T, Ray DE, Carter WG (2008) Albumin binding as a potential biomarker of exposure to moderately low levels of organophosphorus pesticides. Biomarkers 13: 343-363.

6. Carter WG, Tarhoni MH, Ray DE (2010) Analytical approaches to investigate protein-pesticide adducts. J Chromatogr B Analyt Technol Biomed Life Sci 878 : 1312-1319.

7. Tarhoni MH, Vigneswara V, Smith M, Anderson S, Wigmore P, et al. (2011) Detection, quantification, and microlocalisation of targets of pesticides using microchannel plate autoradiographic imagers. Molecules 16: 8535-8551.

8. Vigneswara V, Lowenson JD, Powell CD, Thakur M, Bailey $K$, et al (2006) Proteomic identification of novel substrates of a protein isoaspartyl methyltransferase repair enzyme. J Biol Chem 281: 32619-32629. 